\title{
Quality of life of schizophrenic patients in a tertiary care hospital in Bangladesh
}

\author{
Mir Hasan Shakil Mahmud, ${ }^{1}$ Bushra Yeasmin, ${ }^{2}$ Shipra Mandal ${ }^{3}$ \\ ${ }^{1}$ Lecturer, Department of Occupational Therapy, Bangladesh Health Professions Institute (BHPI), Centre for the Rehabilitation of \\ the Paralysed (CRP), Savar, Dhaka, Bangladesh; ${ }^{2}$ Occupational Therapist, CRP, Dhaka, Bangladesh; ${ }^{3}$ Lecturer, Department of \\ Occupational Therapy, BHPI, CRP, Dhaka, Bangladesh.
}

Article info

Received

Accepted

Number of tables

Number of figures : 03

Number of refs : 29

\section{Correspondence}

Mir Hasan Shakil Mahmud,

E-mail: shakilcrp@yahoo.com

\section{Summary}

Schizophrenia is one of the major mental disorders which affect individual's thinking ability, social interaction or attention. It affects person's entire quality of life. The purpose of the study was to find out the quality of life of schizophrenic patient in Bangladesh. Cross sectional study design was used to conduct this study. The convenient sampling procedure was used throughout the process of participant's selection and the numbers of respondents were 83. The study was carried out at National Institute of Mental Health and Hospital (NIMH), Dhaka. Data was collected by using face to face interview with a structured questionnaire WHOQOL-BREF (The World Health Organization Quality of Life- BREF) scale. It was found that most of the participants lead poor to moderate quality of life in four domains of the WHOQOL-BREF scale. Results showed that mean scores were for physical health (mean 2.7, SD+0.106); psychological health (mean 2.108, SD +0.0787); social relationship (mean 2.226; SD+0.116) and environmental health (mean 2.47; SD+0.077). This study indicated that, quality of life poor on psychological domain. It was also found statistically significance with age and social relationship domain ( $p$ value $0.005<0.05$ ); marital status and physical health domain ( $p$ value $0.004<0.05$ ); educational level and physical health domain ( $p$ value $0.005<0.05$ ) and environmental health domain $(p$ value $0.025<0.05$ ). There were no statistically significant difference between gender and other variables. Schizophrenia affects all aspects of person's life such as physically, psychologically, socially and economically. Schizophrenic patients as well as their family members led very poor quality of life.

Bang J Psychiatry 2015;29(1):30-34

\section{Introduction}

Health is a generalized and universally concerned issue. It refers to physical, mental, social and spiritual well-being of an individual. Mental health is one of the major apparatus which concern ensuring quality of life (QOL). Mentally healthy persons have the ability to work productively. They can adapt easily with life stresses and contribute within their community. ${ }^{1}$ In general, mental illness affects individual functioning through interruption of person's mood, thinking, feeling, behavior and ability to relate to others. ${ }^{2}$ It was reported that every year 1 in 4 people are suffering from mental disorders around the world. Nowadays, 450 million people are suffering from different types of mental disorders. $^{3}$

A study showed that in Bangladesh $6.52 \%$ people were suffered from different psychiatric illnesses in Dasherkandi village near Dhaka city. At the same time $37.4 \%$ people who suffered from schizophrenia. ${ }^{4}$ Schizophrenia is one of foremost psychotic disorder among other types. ${ }^{5}$ Schizophrenia lasts a longer time that affects thinking ability, emotion, making decisions of an individual. ${ }^{6}$ According to Begum ${ }^{7}$ estimated that about 1.3 million people are affected by schizophrenia in Bangladesh.

Patient with schizophrenia lives with different functional disability. Wilkinson acknowledged that patient with schizophrenia cannot retain their life suitably. ${ }^{8}$ QOL is a holistic concept which includes in economic development, social vitality and environmental health and other elements are physical and mental health, social and personal relationships, activities of daily life, productivity. ${ }^{9}$ It was stated that patient with schizophrenia cannot lead their life meaningfully. They loss their reality and become unable to maintain QOL regarding their false beliefs and perception, irrational thinking and behavior. However it is important to maintain their QOL to performing self-care activities, productive work and adapting with new changes. ${ }^{10}$ Another study was carried out on satisfaction on occupational health showed that employment status was important for patient with schizophrenia to control depressive symptoms; they were more pleased on 
everyday occupational status and daily life occupation was more important to lead meaningful QOL. ${ }^{11}$

According to Canadian Association of Occupational Therapists (CAOT), ${ }^{12}$ an occupational therapist worked closely on patient's activities of daily living (ADLs) and made them to engage on meaningful QOL. Pilling suggested that social skills training and cognitive remediation are effective treatment to reduce negative symptoms and their consequences. ${ }^{13}$ Occupational therapists can help social participation and also work for cognitive remediation. The study implemented to find out the relevant problems which coincidence with $\mathrm{QOL}$ in the context of Bangladeshi perspective.

\section{Materials and methods}

The study was a cross sectional study conducted from April 2014 to March 2015. Convenient sampling method (conveniently) was used to collect data from 83 patients with 18 to 45 years age admitted in NIMH. Face to face interview with structured questionnaire of World Health Organization Quality of Life Questionnaire (WHOQOL-BREF) Scale were conducted in a silent place to maintain privacy and ethics. Prior to interviewing, participants read and signed a consent form, whereby a brief description of the study was included. They were informed that the investigation was purely academic and their responses and personal information would be kept confidential. Then instructions were given that the participants could stop at any time if they became uncomfortable. Eighty three cases were included from both inpatient and outpatient department of NIMH. Investigators selected case by checking medical documents and diagnosis by psychiatrists of NIMH. Participants were selected conveniently by following inclusion criteria were aged between 18-45 years and both male and female patients were included for this study. Bangladeshi study supported that most of the people were affected by schizophrenia at the age between 1845 years. $^{14}$ Both male and female are equally affected by schizophrenia. ${ }^{15}$ Participants were excluded following some exclusion criteria were substance user patients because they may become violent. ${ }^{16}$ Patients with schizophrenia may have aggressive or destructive behavior. Sometimes they have the tendency to attack others who care for them or may injured themselves. ${ }^{17}$

The Investigators used WHOQOL-BREF Scale for measuring Quality of Life (QOL). It was initiated in 1991 and developed by World Health Organization (WHO) division of mental health. WHOQOL-100 is a rating scale where survivors ensured the quality from 0 to 100 . Better score defined better QOL. It consists of 26 items and assesses patients under four domains which are physical health, psychological health, social relationship and environmental health. Confidentiality was maintained strictly. On average 60 days were needed to collect data. After proper processing and handling, data were encoded. After thorough cleaning and editing of data, frequency table, summary tables, and appropriate figures were used for presentation of results using appropriate statistical techniques. The research was conducted in full accord with ethical principles.

\section{Results}

The result showed that the age of the respondents ranged between 18 to 45 years. Among 83 participants about 24\% respondents were in 23 to 27 years age group, 31\% were between $28-32$ years, $8 \%$ respondents were between 38 to 42 years age group while $5 \%$ respondents were between 43 to 45 years age group (Figure 1). The result showed that among 83 respondents maximum respondents were male $57 \%$ and $43 \%$ respondents were female (Figure 2). The result revealed that maximum of the respondents were married $82 \%$ and $16 \%$ of the respondents were unmarried while few of the respondents were divorced $2 \%$ (Figure 3). The distribution of respondents' educational level showed that less than primary level $28.9 \%$ and primary completed $24.1 \%$, illiterate was only $18.1 \%$, secondary school $12 \%$, SSC completed $7.2 \%$, HSC completed $06 \%$ and graduated $3.6 \%$ (Table 1 ).

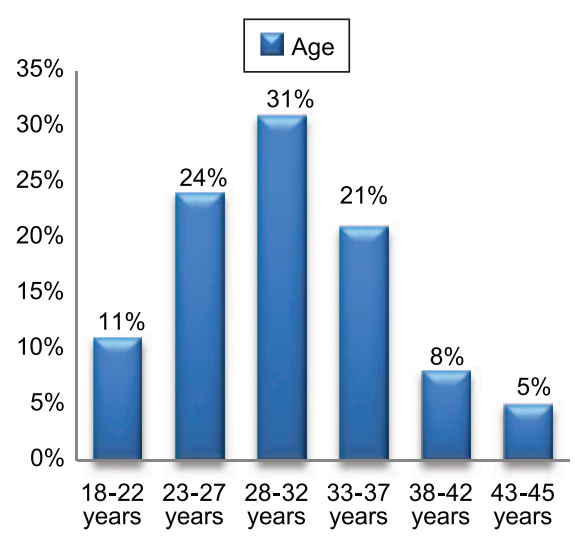

Figure 1: Age range of patients with schizophrenia $(n=83)$

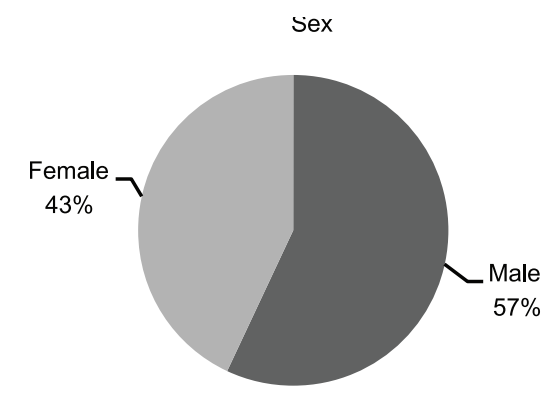

Figure 2: Sex of patients with Schizophrenia $(n=83)$ 


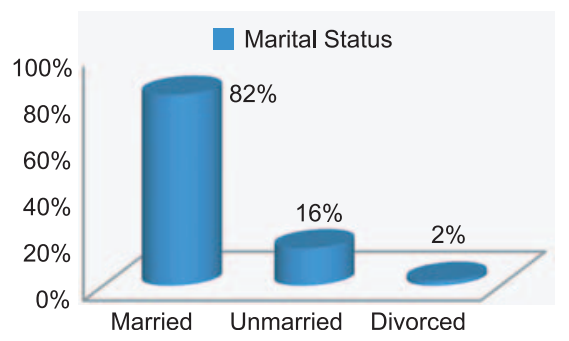

Figure 3: Marital status of patients with Schizophrenia $(n=83)$

Table 1: Distribution of the respondents by educational level $(n=83)$

\begin{tabular}{lcc}
\hline Education & Number & Percentage \\
\hline Illiterate & 15 & 18.1 \\
Signature/ Less than primary & 24 & 28.9 \\
Primary completed & 20 & 24.1 \\
Secondary schooling & 10 & 12.0 \\
SSC completed & 06 & 7.2 \\
HSC completed & 05 & 6.0 \\
Graduated & 03 & 3.6 \\
Total & 83 & 100 \\
\hline
\end{tabular}

The result revealed that the mean (+SD) was $1.83(+0.778)$ for overall QOL of the participants. This study were indicated that poor QOL of the participants. The general health situations of the mean (SD+) was $2.63(+1.044)$. Participants were moderately satisfied with their general health. This study also identified that total SD of physical domain was $(+0.106)$, total SD of psychological domain was +0.0787 , total mean (+SD) was 2.226 $(+0.116)$ for social domain. The study also highlighted that the total mean (+SD) of environmental domain was $2.47(+0.077)$ (Table 2).

The result showed that the distribution of participants QOL and socio- demographic factor was $p$ value for overall QOL (0.249> $0.05)$. According to gender, it showed that $p$ value for overall QOL $(0.706>0.05)$ and overall health $(0.647>0.05)$. In case of marital status, it also indicated that $p$ value was overall QOL $(0.94>0.05)$ and overall health was $(0.669>0.05)$. It identified that there were no statistically significant difference between age and overall QOL, gender and overall QOL and educational level and overall QOL (Table 3).

Table 2: Mean and Standard Deviation (SD) of item scores: WHOQOL-BREF $(n=83)$

\begin{tabular}{lcccc}
\hline QOLDomains & Items & Mean & SD & Range \\
\hline Overall & Overall QOL & 1.83 & 0.778 & $1-4$ \\
& Overall health & 2.63 & 1.044 & $1-4$ \\
Physical health & Total average & 2.7 & 0.106 & $2.76-3.52$ \\
Psychological & Total average & 2.108 & 0.0787 & $2.43-3.24$ \\
Social relationship & Total average & 2.226 & 0.116 & $1-4$ \\
Environmental & Total average & 2.47 & 0.077 & $2.29-3.21$ \\
\hline
\end{tabular}

Table 3: Distribution of participants $Q O L$ and socio-demographic factors $(n=83)$

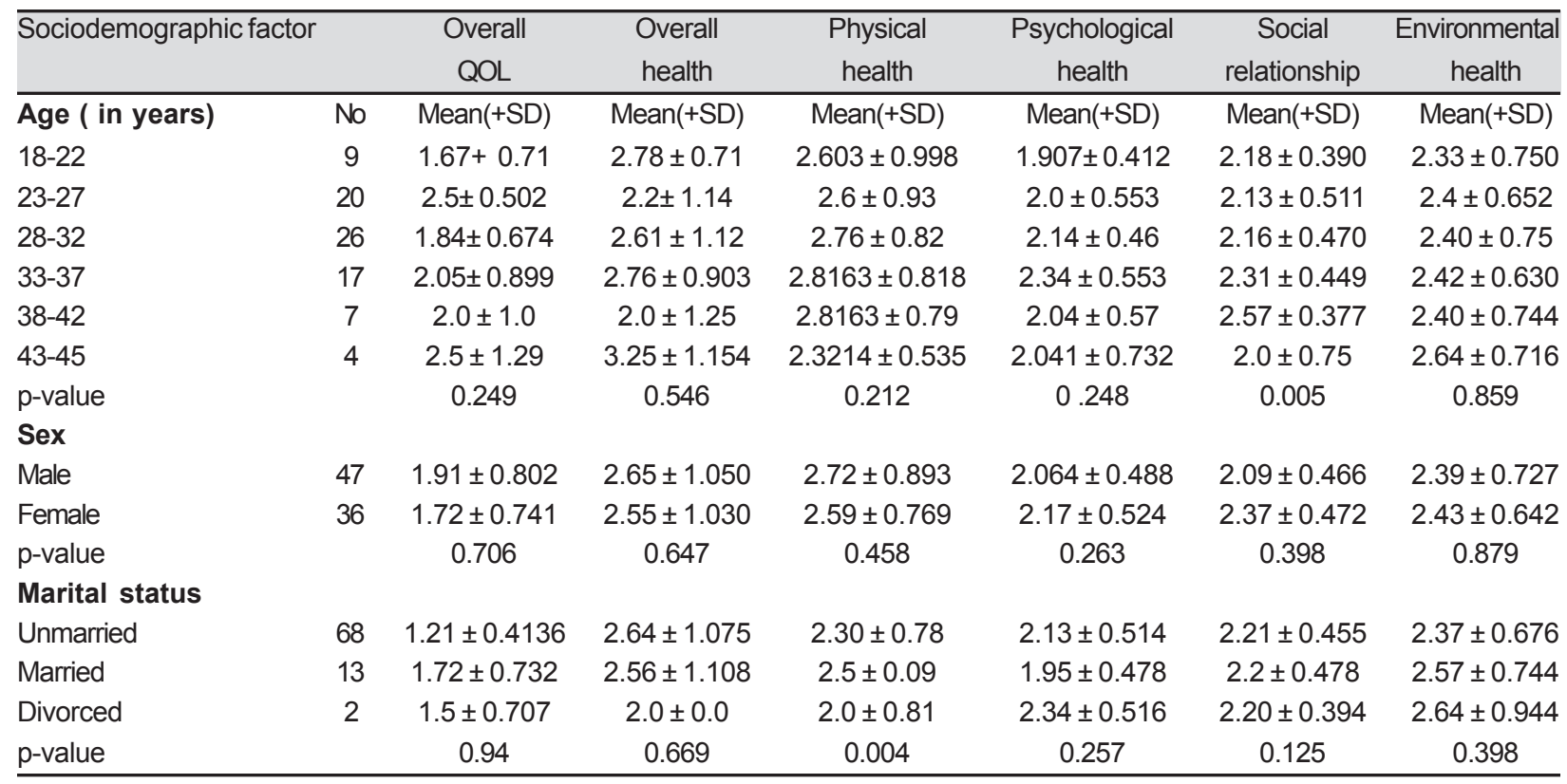




\section{Discussion}

Assess QOL of patients is important for mental health professionals. ${ }^{18}$ Investigators found that score of overall QOL were mean (+SD); $1.83(+0.778)$. It was revealed that the majority of the patients with schizophrenia led poor QOL in Bangladesh. Another study found patients with schizophrenia were neither satisfied nor dissatisfied with their overall QOL and the average score was 3.21 (SD+0.94) with same questionnaire. ${ }^{19}$ VersolaRusso ${ }^{15}$ stated that poor socioeconomic status, poor family and social support, low educational levels, poor transportation facilities, lack of employment were responsible for poor QOL of patients with schizophrenia.

In this study, investigator found that mean score for general health of patient with schizophrenia was 2.63; SD+1.044. This indicated Bangladeshi patients with schizophrenia were poor to moderately satisfaction with their general health. Galuppi ${ }^{18}$ found moderate satisfaction on their general health perception (mean score 3.14). Age is one of the factors among other different factors which influence QOL of patients with schizophrenia. Banerjee ${ }^{20}$ stated that schizophrenia arise late adolescence for males and young adulthood for females. This findings were more similar of World Health Organization reported that was late teens or young adult have more chance to develop schizophrenia. ${ }^{21}$

Sex is another factor which also influences QOL of patients with schizophrenia. Findings of this study indicated that males were more vulnerable to develop schizophrenia rather than females in Bangladesh. According to McGrath ${ }^{22}$ reported that frequency of developing schizophrenia was significantly higher in males than in females. Literature supported that QOL were significantly related to marital status. They found that married or cohabitating had a higher QOL than single and divorced participants. On the other hand, divorced, widowed or separated had a higher QOL than single participant. ${ }^{23}$ Among 83 participants, the maximum number of the participants were married $(81.9 \%)$, the minority numbers $(15.7 \%)$ were single while very only some participants were divorced $(2.4 \%)$.

A study was conducted among community-care schizophrenic patients and long-term hospital-care patients with schizophrenia to know their QOL. They showed educational level influenced the QOL. ${ }^{24}$ Another study reported that low level education affected patients with schizophrenia's QOL that was lower educational level among $75.6 \%$ participants. ${ }^{25}$ Investigators of this study found that $28.9 \%$ education level was less than primary level, $24.1 \%$ was primary completed while only $18.1 \%$ was illiterate. This study also identified that low level education worsen QOL of Bangladeshi patients with schizophrenia. Investigators discovered that among four domains psychological and social domain scores were comparatively lower in this study. Participants expressed that poor QOL on psychological domain in Bangladesh. Radhakrishnan ${ }^{26}$ was conducted a study with same scale. They found that comparatively lower score on psychological and social domain and QOL poork on social domain.

Among four domains Bangladeshi patients with schizophrenia have highest score on physical health domain. Literature supported that patients with Schizophrenia had highest average score on physical health domain and Arithmetic Mean (AM) $=13.22 ; \mathrm{SD}=2.17$ of WHOQOL-BREF scale. ${ }^{27}$ Almeida ${ }^{28}$ indicated that chronic pain worsen $Q O L$ and high frequency of pain among chronic patients with Schizophrenia. On another study, it was stated that poor quality of sleep affected their QOL which lessen their coping ability with stress. ${ }^{29}$

According to Abioda, Morakinyo \& Ibrahim $^{29}$ stated that patients with schizophrenia face difficulties in social relationship might be societal stigmatization. Another study also found lowest scores on the social relationship domain. Patients with schizophrenia were victim of social isolation and discrimination. Investigators found that patient with schizophrenia have poor QOL on social relationship domain in Bangladesh. They were poor to moderate satisfied on personal relationship mean (SD \pm ); (2.63 \pm 1.044$)$, very poor to poor satisfaction on sexual relationship mean $(\mathrm{SD} \pm) ;(1.74 \pm 0.863)$ and they didn't get satisfactory social support mean (SD \pm ); $(2.31 \pm 0.764)$. Galuppi ${ }^{19}$ also found poor satisfaction level on sexual life. They found $59.7 \%$ of males and $54.7 \%$ of females were totally dissatisfied with their sexual relationship.

Participants of this study reported that environmental health domain was poor to moderate rating of QOL. A study was conducted on North-Western Nigerian patients with schizophrenia to know their QOL and found poor score on environment domain. ${ }^{29}$ Another study also found lowest average score ( $A M=12.70 ; S D=2.22)$ on environment domain. ${ }^{29}$ World Health Organization, 2009 reported that around $75 \%$ to $85 \%$ mentally ill people are deprived from proper treatment.

The study revealed that there were no statistically significant with age and overall QOL. On the other hand, there was statistically significant with age and social relationship domain. Galuppi ${ }^{19}$ identified that negative correlation were presented between age and QOL. A study showed, they didn't found statistically significant differences between men and women in specific domains and in general health perception. ${ }^{27}$ Among all the participants indicated that there is statistically significant difference between educational level and physical health domain Cardoso ${ }^{26}$ found that low level education had significantly associated with QOL especially on the social relationship domain. 


\section{Conclusion}

QOL is an immense phase for each and every individual. It is more subjective and indefinable. Measuring QOL is important in mental health sector. Schizophrenia is one of the severe mental disorder which affects person's QOL. In Bangladeshi perspective, patients with schizophrenia lead poor QOL in every sphere of their life. They face difficulty to performing productivity, self-care as well as leisure activities. They are less satisfied with their overall QOL and general health. They get poor social support and become stigmatized. They have poor self-esteem.

\section{References}

1. World Health Organization. Mental disorders affect one in four people. Geneva: World Health Organization; 2001.

2. National Alliance on Mental Illness. Schizophrenia. [Online]. 2014 [Cited 2014 Sept 10]; Available from: URL: http:// www2.nami.org/Content/NavigationMenu/Mental_IIInesses/ Schizophrenia9/Causes.htm

3. World Health Organization. Mental health: a state of wellbeing. [Online]. 2014 [Cited 2014 Sept 10]; Available from: URL: http://www.who.int/features/factfiles/mental_health/en

4. Fahmida A, Wahab MA, Rahman MM. Pattern of psychiatric morbidity among the patients admitted in a private psychiatric clinic. BD J Medi Sci 2009;8(1-2):23-8.

5. Mental Health. Types of Mental IIIness. [Online]. 2015 [Cited 2015 Dec 10]; Available from: URL: http://www.webmd.com/ mental-health/mental-health-types-illness

6. Laurence B. Social Security Disability Benefits for Schizophrenia. [Online]. 2005 [Cited 2015 Oct 22]; Available from: URL: http://www.webmd.com/mental-health/ mental-health-types-illness

7. Begum R. Mental Illness. [Online] 2012 [Cited 2015 Sep 12]; Available from: URL: http://www.banglapedia.org/HT/ M_0268.htm

8. Wilkinson G, Hesdon B, Wild D, Cookson R, Farina C, Sharma $\mathrm{V}$, et al. Self-report quality of life measure for people with schizophrenia: the SQLS. Br J Psychiatry 2000;177(1):42-6.

9. Loga-Zec S, Loga S. Antipsychotics and the quality of life of schizophrenic patients. Psychiatr Danub 2010;22(4):495-7.

10. Alshowkan A, Curtis J, White Y. Quality of life for people with schizophrenia: a literature review. Arab $\mathrm{J}$ of Psych 2012;23(2):122-31.

11. Eklund M, Hansson L, Bejerholm U. Relationships between satisfaction with occupational factors and health-related variables in schizophrenia outpatients. Soc Psychiatry and Psychiatr Epidemiol 2001;36(2):79-83.

12. Canadian Association of Occupational Therapists. Occupational Therapy and Mental Health Care. [Online] 2008 [Cited 2015 Mar 21]; Available from: URL: http:// www.caot.ca/default.asp?page ID $=1290$

13. Pilling S, Bebbington P, Kuipers E, Garety P, Geddes J, Martindale B, et al. Psychol Med 2002;32(5):783-91.

14. Ahmed MN, Azam MNK. Traditional Knowledge and Formulations of Medicinal plants used by the traditional medical practitioners of Bangladesh to treat schizophrenia like psychosis. Schizophrenia Research and Treatment. [Serial Online] 2014 Jun [Cited 2015 Mar 17]; Available from: URL: http://dx.doi.org/10.1155/2014/679810

15. Versola-Russo JM. Cultural and demographic factors of schizophrenia. Inter J Psycho Rehab 2006;10(2):89-103.

16. National Institute of Mental Health. Schizophrenia [Online] 2009 [Cited 2015 Mar 21]; Available from: URL: http:// www.nimh.nih.gov/health/publications/schizophrenia/ index.shtml

17. Hodgins S. Violent behaviour among people with schizophrenia: a framework for investigations of causes, and effective treatment, and prevention. Philosophical Transactions of the Royal Society B: Biological Sciences [Online] 2008 [Cited 2015 Mar 11]; Available from: URL: http://www.ncbi.nlm.nih.gov/pmc/articles/PMC2606714/

18. Galuppi A, Turola M, Nanni M, Mazzoni P, Grassi L. Schizophrenia and quality of life: how important are symptoms and functioning?. Int J Ment Health Syst 2010;4(31):1-8.

19. Connell JJ, O'Cathain A, Brazier J. Measuring quality of life in mental health: are we asking the right questions?. Health and Quality of Life Outcomes. Soc Sci Med 2014;120:12-20.

20. Banerjee A. Cross-cultural variance of schizophrenia in symptoms, diagnosis and treatment. GUJHS 2012;6(2): 18-24.

21. World Health Organization. Schizophrenia [Online] 2015 [Cited 2015 Feb 19]; URL: http://www.who.int/mental_ health/management/schizophrenia/en 22.McGrath JJ. Variations in the Incidence of Schizophrenia: Data versus Dogma. Schizophr Bull 2006;32(1):195-7.

23. Meyer M, Angelis MH, Wurst W, Kühn R. Gene targeting by homologous recombination in mouse zygotes mediated by zinc-finger nucleases. Proc Natl Acad Sci U S A 2010;107(34):15022-6.

24. Rossler W, Salize HJ, Cucchiaro G, Reinhard I, Kernig C. Does the place of treatment influence the quality of life of schizophrenics? Acta Psychiatr Scand 1999;100(2):142-8.

25. Cardoso JC, Clark MS, Viera FA, Bridge PD, Gilles A, Power DM. The secretin G-protein-coupled receptor family: teleost receptors. J Mol Endocrinol 2005;34(3):753-65.

26. Radhakrishnan R, Menon J, Kanigere M, Ashok M, Shobha V, Galgali RB. Domains and determinants of quality of life in schizophrenia and systemic lupus erythematosus. Indian J Psychol Med 2012;34(1):49-55.

27. Makara-Studzinska M, Wo ${ }^{3} y n i a k M$, Partyka I. The quality of life in patients with schizophrenia in community mental health service selected factors. J Pre Cli and Cli Rese 2011;5(1):31-4.

28. Almeida JGD, Braga PE, Neto FL, Pimenta CADM. Chronic pain and quality of life in schizophrenic patients. Rev Bras Psiquiatr 2013;35(1):13-20.

29. Abioda DI, Morakinyo O, Ibrahim A. Quality of life of patients with schizophrenia in North-Western Nigeria. Inter J Psychiatry 2013;2(1):1-7. 